\title{
Sleep apnoea severity independently predicts glycaemic health in nondiabetic subjects: the ESADA study
}

\author{
Brian D. Kent ${ }^{1,2}$, Ludger Grote ${ }^{3}$, Maria R. Bonsignore ${ }^{4,5}$, Tarja Saaresranta ${ }^{6}$, \\ Johan Verbraecken ${ }^{7}$, Patrick Lévy ${ }^{8}$, Pawel Sliwinski ${ }^{9}$, Ruzena Tkacova ${ }^{10,11}$, \\ John-Arthur Kvamme ${ }^{12}$, Ingo Fietze ${ }^{13}$, Jan Hedner ${ }^{3}$ and Walter T. McNicholas ${ }^{1,2}$, \\ on behalf of the European Sleep Apnoea Database collaborators ${ }^{14}$
}

\begin{abstract}
Affiliations: 'School of Medicine and Medical Science, University College Dublin, Dublin, and ${ }^{2}$ Pulmonary and Sleep Disorders Unit, St Vincent's University Hospital, Dublin, Ireland. ${ }^{3}$ Sleep Laboratory, Sahlgrenska University Hospital, Gothenburg, Sweden. ${ }^{4}$ DiBiMIS, University of Palermo, Palermo, and ${ }^{5} \mathrm{CNR}$ Institute of Biomedicine and Molecular Immunology, Palermo, Italy. ${ }^{6}$ Turku University Hospital, Division of Medicine, Department of Pulmonary Diseases and Sleep Research Unit, Department of Physiology, University of Turku, Turku, Finland. ${ }^{7}$ Dept of Pulmonary Medicine, Antwerp University Hospital, Antwerp, Belgium. ${ }^{8}$ Faculté de Médecine, Université Joseph Fourier, INSERM U 1042, Grenoble, France. ${ }^{9}$ Institute of Tuberculosis and Lung Diseases, Warsaw, Poland. ${ }^{10}$ Dept of Respiratory Medicine, P.J. Safarik University, Kosice, ${ }^{11} \mathrm{~L}$. Pasteur University Hospital, Kosice, Slovakia. ${ }^{12}$ ENT Dept, Førde Central Hospital, Førde, Norway. ${ }^{13}$ Center of Sleep Medicine, Charité-Universitätsmedizin Berlin, Berlin, Germany. ${ }^{14} \mathrm{For}$ a list of the ESADA collaborators and their affiliations see the Acknowledgements section.
\end{abstract}

Correspondence: Walter T. McNicholas, Pulmonary and Sleep Disorders Unit, St Vincent's University Hospital, Dublin 4, Ireland. E-mail: Walter.mcnicholasQucd.ie

ABSTRACT Obstructive sleep apnoea (OSA) is associated with increased risk of dysglycaemia but the intimate link of these conditions with obesity makes discerning an independent relationship between them challenging. Glycosylated haemoglobin (HbAlc) levels predict adverse cardiovascular outcomes in nondiabetics but there is a lack of population-level data exploring the relationship of HbAlc with OSA.

A cross-sectional analysis of 5294 participants in the multinational European Sleep Apnoea Cohort (European Sleep Apnoea Database) study was performed, assessing the relationship of OSA severity with HbA1c levels in nondiabetic subjects, with adjustment for confounding factors.

HbAlc levels correlated significantly with OSA severity in univariate analysis. Following adjustment for confounding factors, apnoea-hypopnoea index (AHI) (standardised $\beta 0.158 ; \mathrm{p}<0.001$ ), along with nocturnal hypoxaemia, predicted HbAlc. Adjusted mean HbAlc levels were lower in the lowest AHI quartile $(5.24 \%, 95 \%$ CI $5.21-5.27 \%)$ than in the second $(5.37 \%, 95 \%$ CI $5.34-5.40 \%)$, third (5.44\%, 95\% CI $5.41-5.47 \%)$ or highest $(5.50 \%, 95 \%$ CI 5.46-5.53\%) quartiles. Subjects in the higher quartiles had significantly greater adjusted odds ratios of $\mathrm{HbAlc}$ level $\geqslant 6.0 \%$ than those in the first quartile. In stratified analyses, OSA severity predicted glycaemic health irrespective of sleep study modality, sex, obesity or daytime sleepiness.

OSA severity independently predicts glycaemic health in nondiabetic subjects. Further studies should assess the impact of OSA treatment on glycaemic health and elucidate underlying mechanisms.

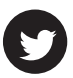

@ERSpublications

Increasing sleep apnoea severity was associated with elevated HbA1c levels in a nondiabetic multinational cohort http://ow.ly/u1RLR

Received: Sept 162013 | Accepted after revision: Feb 192014 | First published online: April 032014

Support statement: B.D. Kent is supported by a grant from the Health Research Board, Ireland (HPF/2009/033). Philips Respironics PLC and ResMed PLC provided the ESADA with two unrestricted grants for support of maintenance of the ESADA Project. Nonfinancial support was provided by the European Sleep Research Society and the European Respiratory Society.

Conflict of interest: Disclosures can be found alongside the online version of this article at www.erj.ersjournals.com

Copyright @ERS 2014 


\section{Introduction}

Obstructive sleep apnoea (OSA) is a highly prevalent disorder affecting at least $4 \%$ of men and $2 \%$ of women in developed countries [1]. OSA is characterised by sleep disordered breathing, whereby collapse of the upper airway during sleep leads to airflow obstruction, recurrent hypoxaemia and reoxygenation, sympathetic overactivity, and microarousals from sleep. Patients with OSA experience excess daytime sleepiness, impaired cognitive function and reduced quality of life. Of more relevance from a physical health perspective, however, is the relationship between sleep disordered breathing and cardiometabolic comorbidities [2]. There is strong evidence that OSA independently relates to prevalent and incident systemic hypertension [3-5], and growing evidence of an independent association with incident coronary artery disease [6], stroke [7], and overall cardiovascular morbidity and mortality [8]. OSA patients are also at increased risk of metabolic dysfunction [9], but the intimate relationship between OSA and obesity has made the definitive identification of any independent role for OSA here difficult.

Type 2 diabetes mellitus (T2DM) is associated with increased risk of cardiovascular disease and death [10], while glycaemic health, as measured by glycosylated haemoglobin (HbAlc), predicts cardiac mortality in nondiabetic subjects [11]. The relationship between OSA and glycaemic health is a topic of increasing clinical and research interest [12]. Community-based studies have suggested that the presence and severity of OSA are independent predictors of insulin resistance [13] and T2DM prevalence [14]. Furthermore, successful initiation of continuous positive airway pressure (CPAP) therapy may be associated with improved insulin sensitivity [15] and reduced HbAlc levels [16], suggesting a potential contributory role for sleep disordered breathing in dysglycaemia.

However, there is a relative paucity of data examining the relationship of OSA with validated long-term cardiovascular mortality risk markers such as HbAlc in nondiabetic subjects. To address these issues, we examined the relationship between OSA and glycaemic health, as measured by HbAlc levels, in a large patient population without an antecedent diagnosis of diabetes attending sleep clinics across Europe. Some of the results of these studies have been previously reported in the form of an abstract [17].

\section{Methods}

The European Sleep Apnoea Cohort (European Sleep Apnoea Database (ESADA)) study is a pan-European, multicentre, prospective study involving 24 sleep clinics across 15 European countries and Israel. The rationale and investigative techniques underlying the establishment of ESADA has been discussed in detail previously [18]. The overall objective of the study is the evaluation of a large cohort of subjects with suspected sleep disordered breathing, in order to identify associations with glycaemic health, metabolic disease, and cardiovascular morbidity and mortality. ESADA employs a web-based collection platform to facilitate transfer of data from individual centres to the central database at the University of Gothenburg (Gothenburg, Sweden) [18].

\section{Subjects}

Enrolment for ESADA commenced in March 2007, with subjects recruited up to July 2012 included in the present study. All subjects aged 18-80 years referred for assessment at participating centres were considered eligible for enrolment in ESADA, unless they met one of the three principal exclusion criteria: treatment of pre-diagnosed OSA syndrome (OSAS) with CPAP or a dental device, severe comorbidity conferring limited life expectancy, and alcohol or drug abuse within 1 year of inclusion. A detailed discussion of the data collection protocols is reported elsewhere [18], but key data recorded for each patient included demographic, anthropometric and clinical variables, including body mass index (BMI), waist/hip ratio, smoking history, alcohol intake, and details of comorbidities and medication use. Subjects had blood drawn for measurement of HbAlc levels. Research ethics committee approval for the study was obtained at each of the participating centres.

\section{Sleep data}

Either cardiorespiratory polygraphy or full polysomnography were performed according to local practice. Polygraphic recordings included a minimum of four recording channels (level 3 devices according to the American Academy of Sleep Medicine (AASM)) and, as a minimum, the following variables were recorded: analysed time, subjective sleep time, apnoea-hypopnoea index (AHI) and oxyhaemoglobin desaturation index (ODI), and mean oxygen saturation measured by pulse oximetry $\left(\mathrm{SpO}_{2}\right)$ and the lowest $\mathrm{SpO}_{2}$ [19]. PSG

This article has supplementary material available from www.erj.ersjournals.com

A press release for this article is available from www.erj.ersjournals.com/site/misc/presspack.xhtml 
studies comprised the following variables in addition to those indicated for polygraphic recordings: total sleep time, sleep efficiency, sleep staging and respiratory disturbance index. Scoring rules applied in ESADA were those proposed by the AASM in 2007 [20]. In a polygraphic recording, a hypopnoea event was scored if there was $\mathrm{a} \geqslant 50 \%$ decrease in the amplitude of a valid measure of airflow during sleep (with an associated $3 \%$ desaturation), or the combination of $\mathrm{a} \geqslant 30 \%$ reduction in airflow with $\geqslant 4 \%$ reduction in $\mathrm{SpO}_{2}$, with a minimum event duration of $10 \mathrm{~s}$. In a PSG study, in addition to the criteria above, a $\geqslant 50 \%$ decrease in airflow associated with an arousal was also classified as hypopnoea. A detailed discussion of respiratory event scoring is reported elsewhere [18]. The Epworth Sleepiness Scale (ESS) was used to assess subjective daytime sleepiness [21].

\section{Outcome measures and statistical analysis}

The principal objective of the present study was to assess the relationship of OSA severity indices with HbA1c levels in nondiabetic subjects enrolled in the ESADA study. Patients were excluded from this analysis if they had an antecedent history of diabetes, were taking diabetic medication and/or had an HbAlc level $\geqslant 6.5 \%$ [22]. Severity of OSA was measured categorically according to AHI and ODI quartiles, with subjects in the first quartile having the lowest AHI or ODI, and serving as a reference category for the estimation of the effect size. Baseline patient characteristics across quartiles were compared using ANOVA with post hoc Bonferroni analysis, Kruskal-Wallis and Mann-Whitney U-tests, and Chi-squared tests for parametric, nonparametric, and categorical variables, respectively. To address the relationship of HbAlc levels with OSAS severity, correlations of patient HbAlc levels measured in Diabetes Control and Compliance Trial (DCCT)-accredited laboratories with OSAS severity measures (AHI and ODI), nocturnal oxygenation (mean nocturnal $\mathrm{SpO}_{2}$ ), demographic and anthropometric measures, clinical variables and ESS scores were assessed by Pearson's or Spearman's correlation coefficients according to distribution. Variables thus identified as having a statistically significant relationship with HbAlc levels were then incorporated into a multivariate linear regression model, with $\mathrm{HbAlc}$ levels as the dependent variable. All statistical models were adjusted for demographic (age, race and sex) and anthropometric (BMI and waist circumference) variables, study site, and relevant clinical factors (smoking history; average sleep duration; statin, oral steroid, diuretic and $\beta$-blocker use; and daytime sleepiness).

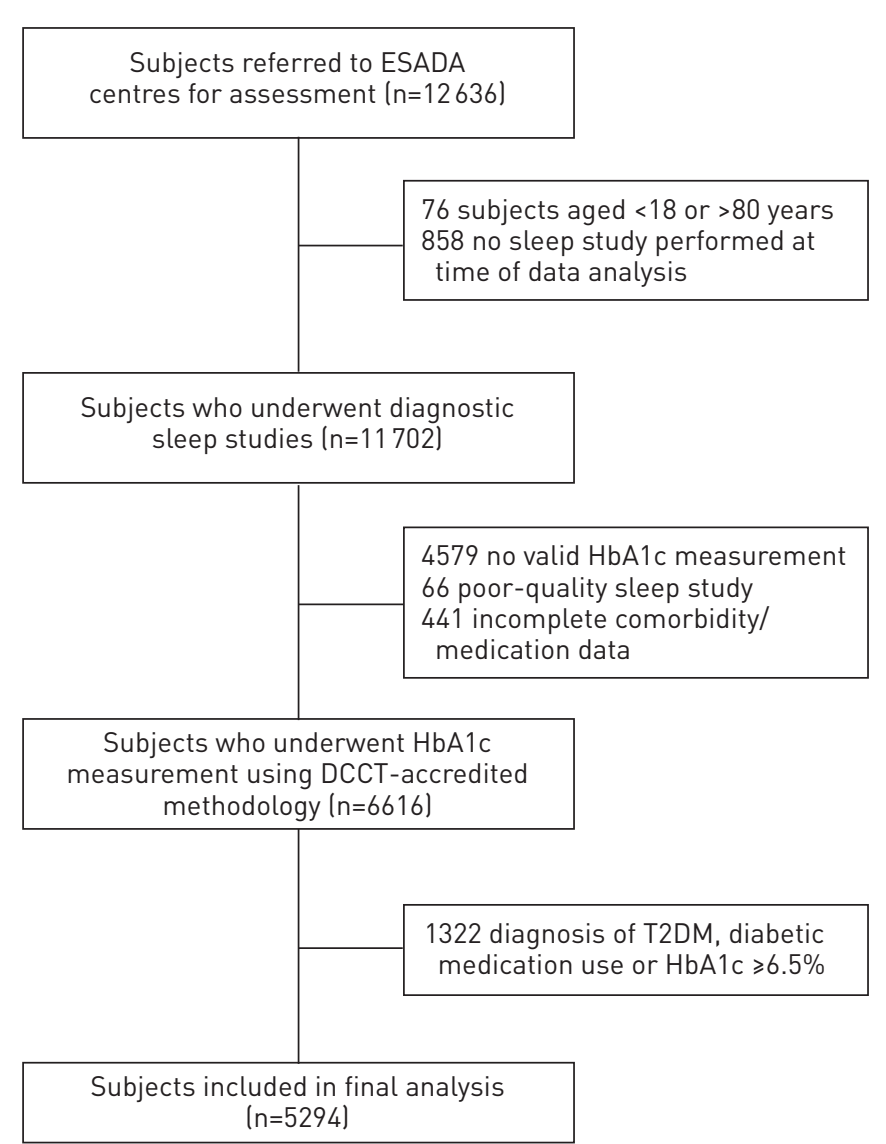

FIGURE 1 European Sleep Apnoea Cohort study patient flow diagram. ESADA: European Sleep Apnoea Database; HbAlc: glycosylated haemoglobin; DCCT: Diabetes Control and Compliance Trial; T2DM: type 2 diabetes mellitus. 


\begin{tabular}{|c|c|c|c|c|c|c|}
\hline & & & \\
\hline & & $0.0-6.1$ & $6.2-16.0$ & $16.1-34.6$ & $34.7-147.3$ & \\
\hline Subjects $\mathrm{n}$ & 5294 & 1329 & 1329 & 1314 & 1322 & \\
\hline Males \% & 70.3 & 56.4 & 66.8 & 76.0 & 82.3 & $<0.001$ \\
\hline Caucasians \% & 92.5 & 94.7 & 92.6 & 93.5 & 89.1 & 0.591 \\
\hline $\mathrm{BMI} \mathrm{kg} \cdot \mathrm{m}^{-2}$ & $30.0 \pm 6.0$ & $28.0 \pm 5.3$ & $29.1 \pm 5.4$ & $30.1 \pm 5.5$ & $32.9 \pm 6.5$ & $<0.001$ \\
\hline Waist circumference $\mathrm{cm}$ & $104.1 \pm 14.5$ & $97.8 \pm 13.4$ & $101.8 \pm 12.3$ & $105.0 \pm 13.3$ & $112.3 \pm 14.9$ & $<0.001$ \\
\hline DBP $\mathrm{mmHg}$ & $82.2 \pm 11.4$ & $80.3 \pm 11.3$ & $81.4 \pm 11.2$ & $82.5 \pm 11.2$ & $84.7 \pm 11.5$ & $<0.001$ \\
\hline ESS score & $9.9 \pm 5.1$ & $9.5 \pm 5.0$ & $9.4 \pm 5.0$ & $9.8 \pm 4.9$ & $10.7 \pm 5.4$ & $<0.001$ \\
\hline Alcohol units per week & $4.4 \pm 7.8$ & $3.4 \pm 6.1$ & $3.8 \pm 6.6$ & $4.8 \pm 8.6$ & $5.7 \pm 9.1$ & $<0.001$ \\
\hline Smokers \% & 24.2 & 25.5 & 23.3 & 23.3 & 25.1 & 0.226 \\
\hline HTN \% & 35.0 & 20.9 & 32.9 & 39.1 & 47.0 & $<0.001$ \\
\hline IHD \% & 6.1 & 3.6 & 7.4 & 6.6 & 6.8 & $<0.001$ \\
\hline$\beta$-blockers \% & 16.4 & 9.7 & 17.5 & 19.1 & 19.2 & $<0.001$ \\
\hline RAS drug $\%$ & 21.3 & 13.0 & 22.2 & 22.4 & 27.8 & $<0.001$ \\
\hline Statins $\%$ & 17.2 & 12.0 & 18.2 & 18.9 & 19.5 & $<0.001$ \\
\hline OCS $\%$ & 1.2 & 1.4 & 0.8 & 1.2 & 1.4 & 0.686 \\
\hline AHI events per $h$ & $23.8 \pm 23.3$ & $2.7 \pm 1.8$ & $10.7 \pm 2.8$ & $24.1 \pm 5.2$ & $57.7 \pm 19.1$ & $<0.001$ \\
\hline Mean $\mathrm{SpO}_{2} \%$ & $93.8 \pm 3.5$ & $94.9 \pm 3.0$ & $94.3 \pm 2.6$ & $93.9 \pm 3.2$ & $92.0 \pm 4.2$ & $<0.001$ \\
\hline $0 D I \geqslant 4 \%$ events per $\mathrm{h}$ & $18.4 \pm 22.1$ & $3.1 \pm 5.0$ & $8.2 \pm 7.7$ & $16.7 \pm 10.3$ & $46.6 \pm 25.1$ & $<0.001$ \\
\hline Cholesterol $\mathrm{mmol} \cdot \mathrm{L}^{-1}$ & $5.26 \pm 1.07$ & $5.26 \pm 1.02$ & $5.27 \pm 1.1$ & $5.28 \pm 1.1$ & $5.24 \pm 1.07$ & 0.348 \\
\hline Triglycerides $\mathrm{mmol} \cdot \mathrm{L}^{-1}$ & $1.81 \pm 1.11$ & $1.59 \pm 0.90$ & $1.77 \pm 1.03$ & $1.89 \pm 1.20$ & $2.00 \pm 1.23$ & $<0.001$ \\
\hline Creatinine $\mathrm{mmol} \cdot \mathrm{L}^{-1}$ & $81.9 \pm 31.4$ & $77.8 \pm 23.5$ & $80.7 \pm 27.3$ & $82.3 \pm 16.6$ & $87.0 \pm 48.3$ & $<0.001$ \\
\hline HbA1c \% & $5.39 \pm 0.56$ & $5.19 \pm 0.59$ & $5.37 \pm 0.55$ & $5.45 \pm 0.52$ & $5.57 \pm 0.52$ & $<0.001$ \\
\hline
\end{tabular}

Data are presented as mean \pm SD unless otherwise stated. AHI: apnoea-hypopnoea index; BMI: body mass index; SBP: systolic blood pressure; DBP: diastolic blood pressure; ESS: Epworth Sleepiness Scale; HTN: hypertension; IHD: ischaemic heart disease; CHF: congestive heart failure; COPD: chronic obstructive lung disease; RAS: renin-angiotensin system; OCS: oral corticosteroids; $\mathrm{SpO}_{2}$ : arterial oxygen saturation measured by pulse oximetry; ODI: oxyhaemoglobin desaturation index; HbA1c: glycosylated haemoglobin.

To further explore the relationship of HbAlc levels with OSAS severity, factorial ANCOVA was performed to generate adjusted mean HbAlc for each AHI or ODI quartile. This analysis was adjusted for study site, and demographic, anthropometric and clinical variables. Adjusted means were compared following Bonferroni's post hoc correction. Finally, in light of recent data demonstrating markedly increased long-term cardiovascular risk among nondiabetic subjects with a baseline HbAlc level $\geqslant 6 \%$ [11], logistic regression analysis was performed to generate adjusted odds ratios for HbAlc $\geqslant 6 \%$ according to OSAS severity quartiles and quartiles of severity for nocturnal hypoxaemia. Analyses stratified by sleep study methodology, obesity, sex and excessive daytime sleepiness (ESS score $>10$ versus $\leqslant 10$ ) were performed to assess interactions between OSAS severity and glycaemic health in clinically relevant subgroups.

Statistical analyses were performed using SPSS version 18.0 statistical software (SPSS Inc., Chicago, IL, USA). A p-value of $<0.05$ was considered statistically significant.

\section{Results}

A total of 6616 subjects enrolled into the ESADA cohort during the study inclusion period had an HbA1c level measured using DCCT-accredited methodology, and $5294(80.0 \%)$ of these had no antecedent diagnosis of T2DM, were not receiving antidiabetic therapy and had an HbAlc level <6.5\% (fig. 1). Descriptive characteristics of this study population, stratified by AHI quartiles, and the distribution of covariates are presented in table 1 . Subjects with more severe OSAS were more likely to be male, were more obese and had a greater burden of cardiometabolic comorbidities than those with no or mild disease. HbAlc levels correlated significantly in univariate analysis with AHI (Spearman $r=0.259, p<0.001$ ), mean $\mathrm{SpO}_{2}$ (Spearman $\mathrm{r}=-0.271, \mathrm{p}<0.001$ ) and ODI (Spearman $\mathrm{r}=0.222, \mathrm{p}<0.001$ ), along with age, obesity 
TABLE 2 Univariate correlations of glycosylated haemoglobin with demographic, clinical and anthropomorphic factors, and indices of obstructive sleep apnoea syndrome severity and nocturnal hypoxaemia

\begin{tabular}{lcc} 
Variable & Correlation coefficient & p-value \\
\hline Age & 0.124 & $<0.001$ \\
SBP & 0.096 & $<0.001$ \\
DBP & 0.064 & $<0.001$ \\
BMI & 0.201 & $<0.001$ \\
Waist circumference & 0.192 & $<0.001$ \\
Neck circumference & 0.177 & $<0.001$ \\
Waist/hip ratio & 0.151 & $<0.001$ \\
ESS score & 0.005 & 0.70 \\
Subjective sleep length & -0.10 & $<0.001$ \\
AHI & 0.259 & $<0.001$ \\
Mean Spo & -0.271 & $<0.001$ \\
ODI & 0.222 & $<0.001$ \\
\hline
\end{tabular}

SBP: systolic blood pressure; DBP: diastolic blood pressure; BMI: body mass index; ESS: Epworth Sleepiness Scale; $\mathrm{AHI}$ : apnoea-hypopnoea index; $\mathrm{SpO}_{2}$ : arterial oxygen saturation measured by pulse oximetry; ODI: oxyhaemoglobin desaturation index.

measures, subjective average sleep duration and blood pressure measurements (table 2). No relationship was seen with subjective daytime sleepiness as measured by the ESS.

A linear regression model was built using variables with significant univariate relationships with HbA1c levels. Following adjustment for age, sex, BMI, neck circumference, sleep duration, smoking status, statin use and systolic blood pressure, AHI remained a significant predictor of HbAlc levels (standardised $\beta=0.160, \mathrm{p}<0.001$ ) (table 3). Similar relationships were seen between HbA1c levels and ODI and mean $\mathrm{SpO}_{2}$ (table 3).

Mean HbAlc levels, adjusted for demographic, anthropometric and clinical variables, were significantly higher in more severe AHI quartiles (fig. 2). Adjusted mean HbAlc was 5.24\% (95\% CI 5.21-5.27\%) in the first (lowest) AHI quartile, 5.37\% (95\% CI 5.34-5.40\%) in the second, 5.44\% (95\% CI 5.41-5.47\%) in the third and 5.50\% (95\% CI 5.46-5.53\%) in the fourth (ANCOVA, $\mathrm{p}<0.001$; post hoc pairwise comparisons with lowest AHI quartile using Bonferroni correction, all $\mathrm{p}<0.001)$

Subjects in the higher AHI quartiles had significantly greater odds of having an HbAlc level $\geqslant 6 \%$ (table 4). In comparison with patients in the first AHI quartile, and following adjustment for demographic factors, smoking status, ESS score, BMI and waist circumference, those in the second, third and fourth AHI quartiles had odds ratios of 1.44 (95\% CI 1.05-1.97), 1.44 (95\% CI 1.04-1.99) and 2.12 (95\% CI 1.53-2.94), respectively, of having $\mathrm{HbAlc}$ levels $\geqslant 6 \%$. Similarly, increasing severity of nocturnal hypoxaemia conferred markedly increased odds of elevated HbAlc, independently of demographic factors and obesity (table 4).

In analyses stratified by sleep study methodology, sleep apnoea severity predicted elevated HbAlc levels in subjects who underwent either PSG or polygraphy. However, among patients who had undergone PSG $(n=2375)$, ODI and mean nocturnal $\mathrm{SpO}_{2}$ were better predictors of HbAlc levels than AHI. For example, although both AHI and ODI maintained a significant relationship with glycaemic health in multivariate stepwise linear regression analyses (online supplementary table 1), adjusted mean $\mathrm{HbAlc}$ levels differed significantly between ODI, but not $\mathrm{AHI}$, quartiles (supplementary fig. 1). Similarly, ODI and mean $\mathrm{SpO}_{2}$ better predicted the likelihood of subjects undergoing PSG having an HbAlc level $\geqslant 6 \%$ following adjustment for confounding factors (supplementary table 2). Conversely, both AHI and ODI remained significant predictors of HbAlc levels in subjects undergoing polygraphy $(\mathrm{n}=2919)$ (supplementary fig. 1, and supplementary tables 3 and 4 ).

Further analyses of subgroups stratified by obesity, sex, and daytime sleepiness (ESS score $>10$ versus $\leqslant 10$ ) demonstrated similar findings to the overall cohort (supplementary tables 5-7 and supplementary figs 2-4). Increasing OSA severity was associated with increased HbAlc levels in men and women, and in those with and without subjective daytime sleepiness. A somewhat stronger relationship was seen between OSA severity indices and HbAlc levels in nonobese than those in obese subjects, but a significant relationship was observed in both groups. 
TABLE 3 Multivariate stepwise regression analysis of relationship of demographic, clinical and anthropomorphic factors, and indices of obstructive sleep apnoea syndrome severity and nocturnal hypoxaemia with glycosylated haemoglobin (Hb1Ac) levels

\begin{tabular}{|c|c|c|c|}
\hline Variable & $\beta(95 \% \mathrm{Cl})$ & Standard $\boldsymbol{\beta}$ & p-value \\
\hline \multicolumn{4}{|l|}{ Model $1^{\#}$} \\
\hline $\mathrm{AHI}$ & $0.004(0.003-0.005)$ & 0.160 & $<0.001$ \\
\hline Body mass index & $0.012(0.009-0.015)$ & 0.127 & $<0.001$ \\
\hline Age & $0.004(0.003-0.006)$ & 0.093 & $<0.001$ \\
\hline Smoking status & $0.138(0.102-0.174)$ & 0.106 & $<0.001$ \\
\hline Subjective sleep length & $0.04(0.029-0.051)$ & 0.098 & $<0.001$ \\
\hline Statin therapy & $0.099(0.057-0.141)$ & 0.067 & $<0.001$ \\
\hline \multicolumn{4}{|l|}{ Model 2" } \\
\hline ODI & $0.003(0.002-0.004)$ & 0.101 & $<0.001$ \\
\hline Body mass index & $0.014(0.011-0.017)$ & 0.148 & $<0.001$ \\
\hline Age & $0.005(0.004-0.006)$ & 0.108 & $<0.001$ \\
\hline Subjective sleep length & $0.039(0.027-0.05)$ & 0.094 & $<0.001$ \\
\hline Smoking status & $0.138(0.101-0.175)$ & 0.106 & $<0.001$ \\
\hline Sex & $0.045(0.011-0.08)$ & 0.037 & 0.011 \\
\hline Statin therapy & $0.092(0.05-0.135)$ & 0.062 & $<0.001$ \\
\hline \multicolumn{4}{|l|}{ Model $3^{+}$} \\
\hline Mean $\mathrm{SpO}_{2}$ & $0.014(0.009-0.019)$ & 0.08 & $<0.001$ \\
\hline Body mass index & $0.016(0.013-0.019)$ & 0.168 & $<0.001$ \\
\hline Age & $0.005(0.004-0.007)$ & 0.106 & $<0.001$ \\
\hline Subjective sleep length & $0.039(0.028-0.050)$ & 0.096 & $<0.001$ \\
\hline Smoking status & $0.127(0.09-0.163)$ & 0.098 & $<0.001$ \\
\hline Sex & $0.054(0.019-0.088)$ & 0.044 & 0.002 \\
\hline Statin therapy & $0.084(0.042-0.127)$ & 0.057 & $<0.001$ \\
\hline
\end{tabular}

AHI: apnoea-hypopnoea index; ODI: oxyhaemoglobin desaturation index; $\mathrm{SpO}_{2}$ : arterial oxygen saturation measured by pulse oximetry. ${ }^{\#}$ : dependent variable, $\mathrm{HbA1c}$; independent variables, $\mathrm{AHI}$, waist circumference, body mass index, age, sex, active smoking, systolic blood pressure, subjective sleep length and statin use; model $\mathrm{R}^{2}=0.093$. ": dependent variable, HbA1c; independent variables, ODI, waist circumference, body mass index, age, sex, active smoking, systolic blood pressure, subjective sleep length and statin use; model $\mathrm{R}^{2}=0.081 .{ }^{+}$: dependent variable, HbA1c; independent variables, mean $\mathrm{SpO}_{2}$, waist circumference, body mass index, age, sex, active smoking, systolic blood pressure, subjective sleep length and statin use; model $\mathrm{R}^{2}=0.081$.

\section{Discussion}

Sleep disordered breathing and dysglycaemia are intimately linked, but the existence of an independent relationship between them, beyond their shared association with obesity, has been difficult to definitively identify. In the largest reported study on this topic to date, we found OSA severity to be an independent predictor of glycaemic health, adding to a growing body of evidence that OSA has an independent association with insulin resistance and impaired glucose tolerance.

The key finding of the present study is the independent relationship seen between OSA severity indices and HbA1c levels in nondiabetic subjects, which remains significant after adjustment for confounding variables. While prior data from the Sleep Heart Health Study and other reports have demonstrated a detrimental effect of sleep disordered breathing on other measures of insulin resistance [13, 23], we evaluated a marker that is a validated predictor of long-term cardiovascular morbidity and mortality in both diabetic and nondiabetic populations $[11,24]$. Therefore, the independent relationship seen between HbAlc levels and sleep disordered breathing severity in this cohort suggests an increased future burden of cardiovascular disease in patients with more severe OSA and more significant nocturnal hypoxaemia.

We observed a significant, if modest, $0.25 \%$ difference in adjusted mean HbAlc between subjects in the mildest AHI quartile and those in the most severe quartile. The best data on the relationship of HbA1c levels with long-term outcomes in nondiabetic subjects is probably provided by the Atherosclerosis Risk in the Community (ARIC) study [11]. In that cohort, subjects with an HbAlc at baseline between 5.5\% and 6.0\% had an $18 \%$ increased risk of death, a $23 \%$ increased risk of incident coronary artery disease and an $86 \%$ increased risk of incident diabetes compared with those with an HbAlc of 5.0-5.5\%, over a median followup time of 14 years. It is a little difficult to assess the $0.25 \%$ difference in adjusted mean HbAlc seen in our cohort in that context, but it is notable that the mildest and most severe AHI quartiles would fall into the two categories mentioned above. We would suggest, however, that the clear increased odds of the more severe OSA severity quartiles having an $\mathrm{HbAlc}$ level $\geqslant 6.0 \%$ is the most important finding in this regard, as 


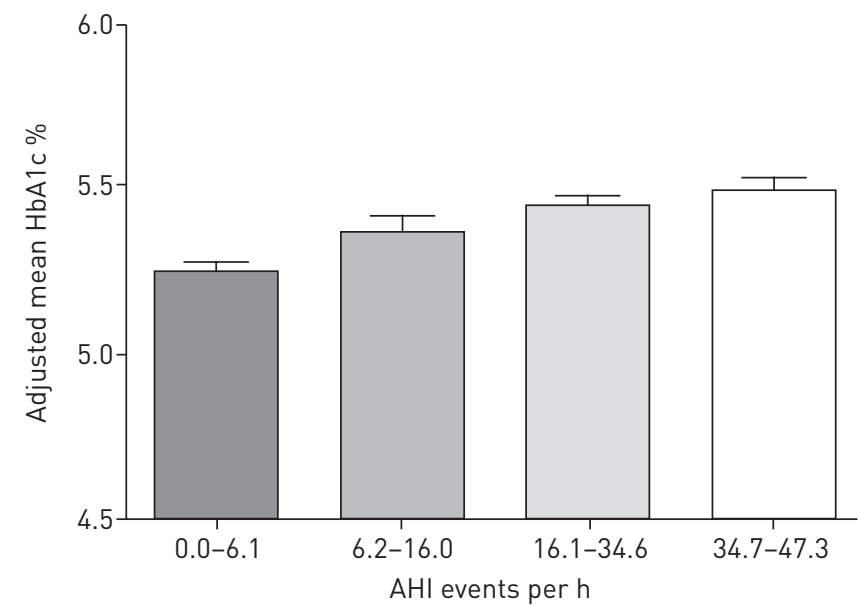

FIGURE 2 Adjusted mean glycosylated haemoglobin (HbAlc) levels by obstructive sleep apnoea syndrome severity quartiles, adjusted for demographic factors (age, race and sex), study site, smoking status, systolic blood pressure, subjective sleep length, statin use, body mass index and waist circumference. Data are presented with $95 \%$ confidence intervals. AHI: apnoeahypopnoea index. ANCOVA: $\mathrm{p}<0.001$.

the data from the ARIC study would indicate that these are the subjects at markedly higher risk of later adverse events [11].

A number of prior reports have suggested that the relationship between OSA and glycaemic health may be particularly strong in sleepy subjects [25]. This has been reported in terms of prevalent T2DM [25] and in terms of insulin resistance in nondiabetic subjects [26]. However, within our population, excessive daytime sleepiness had no significant independent modifying influence on HbAlc levels, which may reflect the clinic-based nature of this cohort or the greater population size studied. In contrast, we observed a particularly marked relationship between HbAlc levels and nocturnal hypoxaemia, as measured by the ODI. We did note a somewhat stronger relationship between OSA severity and HbAlc levels in nonobese patients. While the potential mechanisms underlying this difference remain unclear, one may speculate that increasing concomitant adiposity and adipose tissue dysfunction in obese patients may dilute any detrimental effect of OSA on HbA1c levels.

The present study confirms and extends the findings of the previous report of PRIOU et al. [27], which evaluated the relationship between HbA1c levels and OSA severity in French subjects undergoing investigation for suspected OSA. Importantly, our data are derived from a substantially larger, prospectively studied, multinational population. Moreover, the greater proportion of PSG recordings undertaken in ESADA allows for some potentially important insights into the mechanisms underlying the observed

TABLE 4 Crude and adjusted odds ratios of a glycosylated haemoglobin level $\geqslant 6 \%$ across quartiles of obstructive sleep apnoea syndrome severity and oxygenation indices

AHI events per $h$

p-value

$\begin{array}{llll}0.0-6.1 & 6.2-16.0 & 16.1-34.6 & 34.7-147.3\end{array}$

\begin{tabular}{|c|c|c|}
\hline \multicolumn{3}{|l|}{ AHI } \\
\hline Model $1^{\#}$ & 1 & $2.02(1.53-2.62)$ \\
\hline Model $2^{\top}$ & 1 & $1.64(1.20-2.57)$ \\
\hline Model $3^{+}$ & 1 & $1.44(1.05-1.97)$ \\
\hline \multicolumn{3}{|l|}{ ODI } \\
\hline Model $1^{\#}$ & 1 & $1.68(1.27-2.22)$ \\
\hline Model $2^{\top}$ & 1 & $1.37(1.00-1.87)$ \\
\hline Model $3^{+}$ & 1 & $1.12(0.81-1.54)$ \\
\hline \multicolumn{3}{|l|}{ Mean $\mathrm{SpO}_{2}$} \\
\hline Model $1^{\#}$ & 1 & $1.94(1.43-2.63)$ \\
\hline Model $2^{-}$ & 1 & $1.78(1.27-2.51)$ \\
\hline Model $3^{+}$ & 1 & $1.52(1.07-2.17)$ \\
\hline
\end{tabular}

Data are presented as odds ratio (95\% confidence interval). AHI: apnoea-hypopnoea index; ODI: oxyhaemoglobon desaturation index; SpO $\mathrm{O}_{2}$ arterial oxygen saturation measured by pulse oximetry. " : unadjusted model; " adjusted for demographic factors (race, age and sex), study centre, sleep length, Epworth Sleepiness Scale score and tobacco use; ${ }^{+}$: adjusted as model 2, plus statin use, body mass index and waist circumference. 
association between OSAS severity and glycaemic health. In particular, that nocturnal hypoxaemia appeared to have a stronger relationship with HbAlc levels than AHI among the subjects undergoing PSG may suggest that tissue hypoxia is an important contributor to impaired glycaemic health in these patients, while other sleep-related events may play a less significant role.

White adipose tissue (WAT) is a key endocrine organ in obese subjects [28] and hypoxia has been demonstrated to lead to WAT inflammation and dysfunction [29]. In particular, WAT hypoxia appears to contribute to insulin resistance via a hypoxia-inducible factor-dependent mechanism [30]. Only limited data exist exploring the influence of intermittent hypoxia on WAT function, although intermittent hypoxia does appear to reduce adipocyte secretion of the key antidiabetogenic hormone adiponectin [31]. Other potential drivers of abnormal glucose metabolism in OSA patients include systemic inflammation and oxidative stress [9]. Notably, intermittent hypoxia associated with sleep disordered breathing has been demonstrated in in vitro and clinical studies to lead to increased circulating inflammatory cytokines, such as tumour necrosis factor- $\alpha[32,33]$, which can directly cause WAT to adopt an insulin-resistant, diabetogenic phenotype [34]. Similarly, sympathetic overactivity mediated by OSA may induce lipolysis, with consequent disruption of insulin signalling [35].

There are some important limitations to the present study. First, the reported data are cross-sectional, thereby preventing any robust observations on causality of dysglycaemia in this cohort. A strength of this study is its multinational, multicentre nature. However, this may also be viewed as a limitation in some respects. Sleep diagnostic modalities differed between centres, with approximately half using full PSG and the remainder polygraphy. There was also some variability in the setting of the polygraphy studies, with most performed in the sleep lab, but a number performed on an ambulatory basis. Furthermore, ESADA centres were allowed to use both the "recommended" and "alternative" AASM criteria for respiratory event scoring. Recent data suggest that uniformity of AHI scoring may be significantly reduced by use of the latter [36]. We also cannot exclude the possibility that interlaboratory HbAlc assay variation may have a confounding effect on our results. However, stratification of analyses by sleep testing method continued to show a relationship between OSA severity and nocturnal hypoxaemia, independent of the diagnostic methodology used, and, where feasible, all statistical models were also adjusted to include study site as a covariate.

Not all patients enrolled in the overall ESADA project underwent blood sampling, and a small number of centres utilised International Federation of Clinical Chemistry methods in HbAlc analysis. We cannot exclude the possibility of consequent selection bias contributing to our findings, but it is notable that the demographic, anthropometric and clinical characteristics of the subjects who did not have HbAlc measurement were not significantly different from those who did. Similarly, although we endeavoured to exclude all diabetics from our analysis, there is the possibility that some may not have been successfully identified. Finally, as the cohort studied consisted of subjects attending sleep services, the applicability of our findings to the general population is unproven.

In conclusion, in a large, prospectively recruited, multinational population, we found that OSA severity and nocturnal hypoxaemia independently predict poor glycaemic health in subjects without an antecedent diagnosis of T2DM. Further prospective studies to examine the impact of treatment of sleep disordered breathing on dysglycaemia, as well as mechanistic studies to evaluate the effect of intermittent hypoxia on the adipocyte secretome, are required to tease out the complex interaction between OSA, obesity and metabolic health.

\section{Acknowledgements}

The ESADA study collaborators are Ulla Anttalainen (Turku University Central Hospital, Paimio, Finland), Ferran Barbé (Servei de Pneumologia, Hospital Universitari Arnau de Vilanova and Hospital Santa Maria, Lleida, Spain), Ozen Basoglu (Dept of Chest Diseases, Ege University, Izmir, Turkey), Piotr Bielicki (Dept of Internal Medicine, Pneumonology and Allergology, Warsaw Medical University, Warsaw, Poland), Rio Dumitrascu (Sleep Disorders Center, University of Giessen, Giessen, Germany), Pierre Escourrou (Service d'Éxplorations Fonctionnelles Multidisciplinaires, Hospital Antoine Beclere, Clamart, France), Cristina Esquinas (Servei de Pneumologia, Hospital Universitari Arnau de Vilanova, Lleida, Spain), Marta Kumor (Dept of Internal Medicine, Pneumonology and Allergology, Warsaw Medical University, Warsaw, Poland), Lena Lavie and Peretz Lavie (Centre for Sleep Medicine, Technion Institute of Technology, Haifa, Israel) Carolina Lombardi (Center for Sleep Disorders, Istituto Auxologico Italiano, Ospedale San Luca, Milan, Italy), Oreste Marrone (CNR Institute of Biomedicine and Molecular Immunology, Palermo, Italy), Juan Fernando Masa (Hospital San Pedro de Alcàntara, Cáceres, CIBERES, Madrid, Spain), Josep M. Montserrat (Hospital Clinic I Provincial de Barcelona, Barcelona, Spain), Geraldine Nolan (Pulmonary and Sleep Disorders Unit, St. Vincent's University Hospital, Dublin, Ireland), Gianfranco Parati (Center for Sleep Disorders, Istituto Auxologico Italiano, Ospedale San Luca, Milan, Italy), Athanasia Pataka (Respiratory Failure Unit, G. Papanikolaou Hospital, Thessalonika, Greece), Thomas Penzel (Center of Sleep Medicine, Charité-Universitätsmedizin Berlin, Berlin, Germany), Jean-Louis Pépin (Faculté de Médecine, Université Joseph Fourier, INSERM U 1042, Grenoble, France), Robert Plywaczewski (Institute of Tuberculosis and Lung Diseases, Warsaw, Poland), Martin Pretl (Sleep Disorders Center, Department of Neurology, 
Charles University, Prague, Czech Republic), Renata Riha (Dept of Sleep Medicine, Edinburgh Royal Infirmary, Edinburgh, UK), Silke Ryan (School of Medicine and Medical Science, University College Dublin, Dublin, Ireland), Gabriel Roisman (Unité de Médecine du Sommeil, Hopital Antoine-Beclere, Clamart, France), Richard Schulz (Sleep Disorders Center, University of Giessen, Giessen, Germany), Richard Staats (Dept of Respiratory Medicine, Hospital de Santa Maria, Lisbon, Portugal), Paschalis Steiropoulos (Sleep Unit, Department of Pneumonology, Democritus University of Thrace, Alexandroupolis, Greece), Giedvar Varoneckas (Institute of Psychophysiology and Rehabilitation, Palanga, Lithuania), A. Vitols (Institute of Cardiology, University of Latvia, Riga, Latvia) and Heleen Vrints (Dept of Pulmonary Medicine, Antwerp University Hospital, Antwerp, Belgium).

\section{References}

1 Young T, Palta M, Dempsey J, et al. The occurrence of sleep-disordered breathing among middle-aged adults. N Engl J Med 1993; 328: 1230-1235.

2 McNicholas WT, Bonsignore MR. Sleep apnoea as an independent risk factor for cardiovascular disease: current evidence, basic mechanisms and research priorities. Eur Respir J 2007; 29: 156-178.

3 Peppard PE, Young T, Palta M, et al. Prospective study of the association between sleep-disordered breathing and hypertension. N Engl J Med 2000; 342: 1378-1384.

4 Nieto FJ, Young TB, Lind BK, et al. Association of sleep-disordered breathing, sleep apnea, and hypertension in a large community-based study. Sleep Heart Health Study. JAMA 2000; 283: 1829-1836.

5 Marin JM, Agusti A, Villar I, et al. Association between treated and untreated obstructive sleep apnea and risk of hypertension. JAMA 2012; 307: 2169-2176.

6 Peker Y, Carlson J, Hedner J. Increased incidence of coronary artery disease in sleep apnoea: a long-term follow-up. Eur Respir J 2006; 28: 596-602.

7 Redline S, Yenokyan G, Gottlieb DJ, et al. Obstructive sleep apnea-hypopnea and incident stroke: the sleep heart health study. Am J Respir Crit Care Med 2010; 182: 269-277.

8 Punjabi NM, Caffo BS, Goodwin JL, et al. Sleep-disordered breathing and mortality: a prospective cohort study. PLoS Med 2009; 6: e1000132.

9 Bonsignore MR, McNicholas WT, Montserrat JM, et al. Adipose tissue in obesity and obstructive sleep apnoea. Eur Respir J 2012; 39: 746-767.

10 Haffner SM, Lehto S, Ronnemaa T, et al. Mortality from coronary heart disease in subjects with type 2 diabetes and in nondiabetic subjects with and without prior myocardial infarction. N Engl J Med 1998; 339: 229-234.

11 Selvin E, Steffes MW, Zhu H, et al. Glycated hemoglobin, diabetes, and cardiovascular risk in nondiabetic adults. N Engl J Med 2010; 362: 800-811.

12 Shaw JE, Punjabi NM, Wilding JP, et al. Sleep-disordered breathing and type 2 diabetes: a report from the International Diabetes Federation Taskforce on Epidemiology and Prevention. Diabetes Res Clin Pract 2008; 81: 2-12.

13 Punjabi NM, Shahar E, Redline S, et al. Sleep-disordered breathing, glucose intolerance, and insulin resistance: the Sleep Heart Health Study. Am J Epidemiol 2004; 160: 521-530.

14 Reichmuth KJ, Austin D, Skatrud JB, et al. Association of sleep apnea and type II diabetes: a population-based study. Am J Respir Crit Care Med 2005; 172: 1590-1595.

15 Lam JC, Lam B, Yao TJ, et al. A randomised controlled trial of nasal continuous positive airway pressure on insulin sensitivity in obstructive sleep apnoea. Eur Respir J 2010; 35: 138-145.

16 Sharma SK, Agrawal S, Damodaran D, et al. CPAP for the metabolic syndrome in patients with obstructive sleep apnea. N Engl J Med 2011; 365: 2277-2286.

17 Kent BD, Grote L, Bonsignore MR, et al. Severity of sleep disordered breathing is an independent predictor of glycemic health: the European Sleep Cohort (ESADA) study. Am J Respir Crit Care Med 2012; 185: A5379.

18 Hedner J, Grote L, Bonsignore M, et al. The European Sleep Apnoea Database (ESADA): report from 22 European sleep laboratories. Eur Respir J 2011; 38: 635-642.

19 Practice parameters for the use of portable recording in the assessment of obstructive sleep apnea. Standards of Practice Committee of the American Sleep Disorders Association. Sleep 1994; 17: 372-377.

20 Iber C, Ancoli-Israeli S, Chesson A, et al. The AASM Manual for the scoring of sleep and associated events: rules, terminology and technical specifications. 1st Edn. Westchester, American Academy of Sleep Medicine, 2007.

21 Johns MW. A new method for measuring daytime sleepiness: the Epworth sleepiness scale. Sleep 1991; 14: 540-545.

22 American Diabetes Association. Diagnosis and classification of diabetes mellitus. Diabetes Care 2011; 34: Suppl 1. S62-S69.

23 Ip MS, Lam B, Ng MM, et al. Obstructive sleep apnea is independently associated with insulin resistance. Am J Respir Crit Care Med 2002; 165: 670-676.

24 Selvin E, Marinopoulos S, Berkenblit G, et al. Meta-analysis: glycosylated hemoglobin and cardiovascular disease in diabetes mellitus. Ann Intern Med 2004; 141: 421-431.

25 Ronksley PE, Hemmelgarn BR, Heitman SJ, et al. Obstructive sleep apnoea is associated with diabetes in sleepy subjects. Thorax 2009; 64: 834-839.

26 Barcelo A, Barbe F, de la Pena M, et al. Insulin resistance and daytime sleepiness in patients with sleep apnoea. Thorax 2008; 63: 946-950.

27 Priou P, Le Vaillant M, Meslier N, et al. Independent association between obstructive sleep apnea severity and glycated hemoglobin in adults without diabetes. Diabetes Care 2012; 35: 1902-1906.

28 Trayhurn P, Wang B, Wood IS. Hypoxia and the endocrine and signalling role of white adipose tissue. Arch Physiol Biochem 2008; 114: 267-276.

29 Wang B, Wood IS, Trayhurn P. Dysregulation of the expression and secretion of inflammation-related adipokines by hypoxia in human adipocytes. Pflugers Arch 2007; 455: 479-492.

30 Regazzetti C, Peraldi P, Gremeaux T, et al. Hypoxia decreases insulin signaling pathways in adipocytes. Diabetes 2009; 58: 95-103.

31 Magalang UJ, Cruff JP, Rajappan R, et al. Intermittent hypoxia suppresses adiponectin secretion by adipocytes. Exp Clin Endocrinol Diabetes 2009; 117: 129-134.

32 Ryan S, Taylor CT, McNicholas WT. Selective activation of inflammatory pathways by intermittent hypoxia in obstructive sleep apnea syndrome. Circulation 2005; 112: 2660-2667. 
33 Ryan S, Taylor CT, McNicholas WT. Predictors of elevated nuclear factor- $\mathrm{kB}$-dependent genes in obstructive sleep apnea syndrome. Am J Respir Crit Care Med 2006; 174: 824-830.

34 Hotamisligil GS, Shargill NS, Spiegelman BM. Adipose expression of tumor necrosis factor-alpha: direct role in obesity-linked insulin resistance. Science 1993; 259: 87-91.

35 Drager LF, Jun JC, Polotsky VY. Metabolic consequences of intermittent hypoxia: relevance to obstructive sleep apnea. Best Pract Res Clin Endocrinol Metab 2010; 24: 843-851.

36 Kuna ST, Benca R, Kushida CA, et al. Agreement in computer-assisted manual scoring of polysomnograms across sleep centers. Sleep 2013; 36: 583-589. 